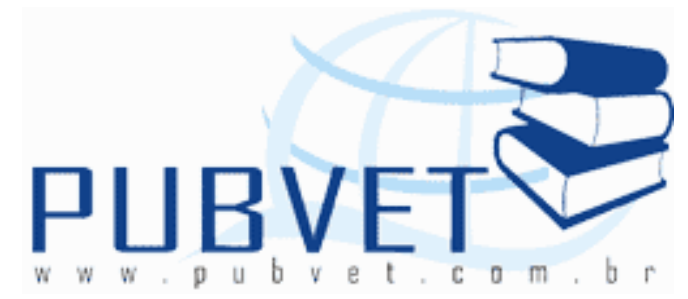

PUBVET, Publicações em Medicina Veterinária e Zootecnia.

\title{
Mastite caprina: etiologia e epidemiologia: revisão de literatura
}

Clautina Ribeiro de Moraes da Costa $^{1}$, Matheus Levi Tajra Feitosa ${ }^{2}$, Gerson Tavares Pessoa ${ }^{3}$, Dayseanny de Oliveira Bezerra³ ${ }^{3}$ Maíra Soares Ferraz ${ }^{3}$, Maria Acelina Martins de Carvalho ${ }^{4}$

${ }^{1}$ Bióloga, aluna de Doutorado em Biotecnologia do Programa de Pós-graduação RENORBIO. Universidade Federal do Piauí, Teresina-PI, Brasil.

${ }^{2}$ Médico Veterinário, Pós Doutorando do Programa de Pós Graduação em Ciência Animal. Universidade Federal do Piauí, Teresina-PI, Brasil.

${ }^{3}$ Médico Veterinário, Programa de Pós Graduação em Ciência Animal da Universidade Federal do Piauí, Teresina-PI, Brasil.

${ }^{4}$ Docente do Departamento de Medicina Veterinária, Centro de Ciências Agrárias, Universidade Federal do Piauí, Teresina-PI, Brasil.

\section{Resumo}

A caprinocultura de leite vem se desenvolvendo cada vez mais no Brasil, no entanto, um dos grandes problemas para seguir padrão de qualidade é ter um rebanho livre de mastite. Inflamação da glândula mamária, que tem ocasionado prejuízos para o criador. Os principais micro-organismos responsáveis pelos casos de mastite em caprinos e ovinos no Brasil são os Staphylococcus spp. O objetivo desta revisão é fornecer informações recentes (2001 a 2011) sobre mastite em pequenos ruminantes, sobretudo em caprinos, abrangendo todos os aspectos importantes para maior compreensão 
COSTA, C.R.M. et al. Mastite caprina: etiologia e epidemiologia: revisão de literatura. PUBVET, Londrina, V. 7, N. 8, Ed. 231, Art. 1530, Abril, 2013.

da mesma, como sua etiologia, epidemiologia, aspectos de controle e profilaxia.

Palavras-chave: Cabra, glândula mamária, inflamação

\title{
Caprine Mastitis: Etiology and epidemiology: Literature Review
}

\begin{abstract}
Milk goats has been developing increasingly in Brazil, however, a major problem to follow a pattern and quality is having a free herd mastitis. Inflammation of the mammary gland, which has caused damage to the creator. The main micro-organisms responsible for mastitis in goats and sheep in Brazil are Staphylococcus spp. The aim of this review is to provide recent (2001 to 2011) on mastitis in small ruminants, especially goats, covering all important aspects for better understanding of it, as its etiology, epidemiology, prevention and control aspects.
\end{abstract}

Keywords: Goat, mammary gland, inflammation

\section{INTRODUÇÃO}

A criação de caprinos tem uma grande importância social e econômica para os países em desenvolvimento. A caprinocultura de leite vem se desenvolvendo cada vez mais em termos de quantidade, entretanto, o sucesso da atividade está intimamente ligado à produção de leite com excelente higiene e qualidade, e um dos grandes desafios é ter um rebanho livre de mastite, ou pelo menos a sua existência em níveis aceitáveis.

A mastite é uma inflamação da glândula mamária, que tem ocasionado prejuízos para o criador através da diminuição da qualidade e quantidade de leite, e ainda pela necessidade de descartar o animal. A origem da mastite é ampla, podendo ser ocasionada por traumas durante o manejo ou a ordenha, ainda pela presença de microrganismos (ANDERSON et al. 2004). Os principais microrganismos responsáveis pelos casos de mastite em caprinos e ovinos no 
COSTA, C.R.M. et al. Mastite caprina: etiologia e epidemiologia: revisão de literatura. PUBVET, Londrina, V. 7, N. 8, Ed. 231, Art. 1530, Abril, 2013.

Brasil são os Staphylococcus spp. (MOTA, 2008; LANGONI et al. 2006). Dentre os microrganismos deste gênero destacam-se como mais incidentes os Staphylococcus coagulase negativa (SCN), e os que causam maiores prejuízos para o rebanho são os Staphylococcus coagulase positiva (SCP), tendo como principal o Staphylococcus aureus.

Um fator determinante para a mastite é o período de lactação, onde o animal encontra-se mais suscetível a mastite infecciosa, e no período seco observa-se maior freqüência de mastite ambiental (PRESTES et al. 2002). Além destes aspectos existem ainda os fatores individuais dos animais como: resistência natural da glândula mamária, estágio da lactação, hereditariedade, idade do animal, espécie, infectividade e patogenicidade do agente.

Para se fazer o diagnóstico da mastite pode ser realizado métodos diretos e indiretos. Os exames diretos baseiam-se na identificação do agente etiológico. E os métodos indiretos se fundamentam na evolução e intensidade da reação inflamatória (MOTA, 2008).

O objetivo desta revisão é fornecer informações recentes (2001 a 2011) sobre mastite em pequenos ruminantes, sobretudo em caprinos, abrangendo os aspectos importantes para maior compreensão da mesma, como sua etiologia, epidemiologia, aspectos de controle e profilaxia.

\section{REVISÃO DE LITERATURA}

A atividade de criação de caprinos é importante para o estabelecimento de muitas cidades, através do fornecimento de leite, carne e pele. Os caprinos trazidos ao Brasil, pelos portugueses no início da colonização se adaptaram principalmente nas regiões de clima inóspitos como o Nordeste (CORDEIRO, 2006).

Desta forma os caprinos têm uma grande importância econômica e social no Brasil, sobretudo para essa região, é também uma das primeiras espécies domesticadas pelo homem, no contexto da ciência mundial, e bem adaptada na região em face de suas características como: rusticidade, praticidade, fácil 
COSTA, C.R.M. et al. Mastite caprina: etiologia e epidemiologia: revisão de literatura. PUBVET, Londrina, V. 7, N. 8, Ed. 231, Art. 1530, Abril, 2013.

adaptação e sobrevivência em condições inóspitas, por isso, no Brasil os caprinos se adaptam bem em regiões com ecossistema cerrado e caatinga.

Devemos considerar ainda que a caprinocultura, é uma atividade importante para o nordestino, porque diante das condições ambientais desfavoráveis, a caprinocultura disponibiliza grande variedade de produtos que são essenciais à subsistência do homem. Por isso, maiores cuidados devem ser tomados e maiores investimentos devem ser empregados.

A caprinocultura desenvolve os seus potenciais, principalmente de carne e leite; dois produtos de excelente qualidade e valor nutritivo, assim têm-se investido muito em marketing, resultando em maior aprimoramento na criação e aumento na produção leiteira e com isso também maior preocupação com a qualidade do leite (GOMES et al. 2004). Portanto, é importante melhorar a sanidade dos animais, adotando medidas de manejo, que venham prevenir doenças e também diagnosticar e tratar as mesmas.

Uma das infecções que traz muitos prejuízos para a caprinocultura é a mastite que é uma inflamação das glândulas mamárias, que pode ter como causas um agente infeccioso, químico, mecânico ou térmico que agride a glândula mamária. É uma doença que preocupa criadores de caprinos, pela baixa qualidade do leite e por gerar graves prejuízos econômicos e problemas à saúde pública (GOMES et al. 2004). Todas as medidas preventivas são importantes para evitá-las. Faremos uma abordagem da mastite em caprinos para maior compreensão e detalhamento da mesma.

Os tetos correspondem a uma região altamente inervada e vascularizada (FRANDSON et al. 2005), é um local que diante de uma infecção proporciona que seja rapidamente desencadeado um processo inflamatório, sendo mais comum em período de lactação, comprometendo a viabilidade leiteira do animal.

Embora a própria anatomia das glândulas mamárias favoreça a sanidade, através de estruturas que dificultam a entrada de microrganismos se não houver cuidados de manejo, sobretudo, durante a ordenha o animal poderá se expor a agentes infecciosos que provocam a mastite. 
COSTA, C.R.M. et al. Mastite caprina: etiologia e epidemiologia: revisão de literatura. PUBVET, Londrina, V. 7, N. 8, Ed. 231, Art. 1530, Abril, 2013.

A literatura aponta que as práticas de manejo inadequadas aumentam a susceptibilidade à mastite. De fato pode ser identificado mediante a contagem de células somáticas (CCS) no pós-parto, indicando que o animal foi exposto à má condição ambiental, ou houve ineficiência no tratamento de infecções no período seco.

A forma como o animal é ordenhado é um fator que pode predispor significativamente à mastite, se esta ocorrer de forma manual, o ordenhador deve ter muitos cuidados higiênicos, como lavagem das mãos, limpeza dos tetos, entre outros; e se a ordenha for realizada de forma mecanizada os equipamentos devem ser rigorosamente sépticos.

Outros aspectos são predisponentes a mastite como: patógenos podem ser facilmente transferidos de um animal para outro se não houver cuidados na limpeza (lavagem e secagem) dos tetos e das mãos do ordenhador ou das ordenhadeiras; difusão dos microrganismos entre os quartos mamários, através de movimentos reversos do leite proporcionado pelas flutuações no sistema de vácuo, além de poder causar traumas nas tetas e o processo não ser concretizado, ficando resquícios de leite nas tetas e com isso proporcionando um meio de crescimento bacteriano excelente; o próprio canal do teto se não estiver bem contraído pode propiciar à exposição de patógenos (SHEARER, 2001).

A mastite em ruminantes é um assunto que vem sendo muito investigado, no entanto as pesquisas sobre a mastite no úbere de cabras são mais escassas, ou incompletas. Um dos aspectos que não está concretamente compreendido ou finalizado são os testes diagnósticos isolados, que não apresentam completa confiabilidade, uma vez que vários aspectos externos devem ser considerados para análise do diagnóstico.

A literatura vem apresentando em termos de diagnóstico que devem ser feitos vários testes simultaneamente para analisar os resultados em conjunto. A lactogênese e período seco constituem eventos reprodutivos que influenciam na susceptibilidade à mastite, embora a glândula mamária seja protegida por uma variedade de mecanismos de defesas naturais, barreiras físicas como o 
COSTA, C.R.M. et al. Mastite caprina: etiologia e epidemiologia: revisão de literatura. PUBVET, Londrina, V. 7, N. 8, Ed. 231, Art. 1530, Abril, 2013.

canal e o esfíncter do teto, e ainda, as proteínas bactericidas. O esfíncter do teto mantém-se fechado entre as ordenhas, porém, após a ordenha, o canal do teto torna-se dilatado e permanece por, aproximadamente, 30 a 120 minutos, sendo necessário alimentar o animal nesse período, pois, ao ficar em pé, o esfíncter se fechará em menos de duas horas (PRESTES et al. 2002).

Adicionalmente, Araújo \& Gheller (2005) apontam outras barreiras físicas importantes compostas, pela queratina, células epiteliais descamadas, ácidos graxos e proteínas catiônicas que atua na defesa inespecífica da glândula mamária.

Com relação às causas do processo inflamatório desencadeado nas glândulas mamárias pode ser usualmente desencadeado por bactérias (BLAGITZ et al. 2008; AULRICH; BARTH, 2008). E dependendo da maneira como se manifesta pode ser classificada como mastite clínica, sub-clínica ou crônica.

A mastite traz muitos prejuízos para rebanhos caprinos de corte, ela é responsável pelo atraso no desenvolvimento dos cabritos, resultando em um decréscimo da taxa de ganho de peso e aumento da mortalidade neonatal, além de poder levar ao descarte de animais. As formas clínicas inaparentes, produzem maior efeito na redução da produção e na qualidade do leite, levando a prejuízos maiores (BLAGITZ et al. 2008).

Como citado anteriormente o desencadeamento da mastite está vinculado ao animal (hospedeiro), ao agente etiológico e/ou ao meio ambiente, fazendo com que seja uma enfermidade de origem multifatorial (HURLEY; MORIN, 2001), por isso a sua prevenção e o seu controle estão intimamente relacionados e/ou dependem do conhecimento dos padrões de ocorrência da doença.

Dentre os agentes infecciosos a mastite pode ser provocada pela prevalência de vários tipos de patógenos isolados ou em associação (KOOP et al. 2010). Devemos considerar que a epidemiologia da mastite é bastante variável entre as espécies, devendo ser considerado aspectos como a 
COSTA, C.R.M. et al. Mastite caprina: etiologia e epidemiologia: revisão de literatura. PUBVET, Londrina, V. 7, N. 8, Ed. 231, Art. 1530, Abril, 2013.

quantidade, a patogenicidade e a infectividade do agente envolvido e desta forma os fatores de risco diferem conforme essas características.

A mastite infecciosa é causada por uma ampla variedade de microrganismos, subdivididos em agentes contagiosos e ambientais (BYENG et al. 2007).

Os agentes contagiosos são transmitidos fundamentalmente no momento da ordenha ou no ato de mamar. Causada principalmente por Staphylococcus aureus, Staphylococcus epidermidis, Streptococcus agalactiae, Streptococcus dysgalactiae, Corynebacterium sp. Os agentes ambientais são transmitidos na ordenha e entre-ordenhas, representados principalmente pelas enterobactérias (Escherichia coli, Klesbsiella pneumoniae, Enterobacter aerogenes), fungos, algas, Nocardia sp e Pseudomonas aeruginosa (RADOSTITS et al. 2002).

Em pesquisa realizada por Medeiros et al. (2009) os patógenos mais prevalentes na mastite caprina são dos gêneros Staphylococcus e Pseudomonas, observando como resultados que; $43,7 \%$ de mastite são causadas por Staphylococcus coagulase negativa e 35,4\% são causadas por $S$. Aureus e 12,4\% por Pseudomonas aeruginosa.

O S. Aureus é mundialmente conhecido como causador de várias doenças purulentas e de fato são apontados na literatura como os principais agentes etiológicos da infecção intramamária em caprinos. Este gênero de bactérias pode ser classificado em dois grupos: os Staphylococcus coagulase positiva (SCP) uma vez que possuem a capacidade de produzir a enzima coagulase, e os Staphylococcus coagulase-negativa (SCN), que não produzem a enzima (CONTRERAS et al. 2007; MORONI et al. 2005).

Para Medeiros et al. (2009) dos 291 casos isolados de mastite que foram identificados em cabras, $58,4 \%$ foram classificados como SCN, $12,7 \%$ como SCP e 28,9\% como Staphylococcus aureus. Freitas et al. (2005) também verificaram que SCN foi o microrganismo mais isolado de leite de vacas com mastite subclínica no Agreste do Estado de Pernambuco.

Resultados semelhantes foram encontrados por Radostits et al. (2002); Bergonier \& Berthelot (2003); Aulrich \& Barth (2008). Staphylococcus 
COSTA, C.R.M. et al. Mastite caprina: etiologia e epidemiologia: revisão de literatura. PUBVET, Londrina, V. 7, N. 8, Ed. 231, Art. 1530, Abril, 2013.

coagulase negativo também foram identificados como os microrganismos mais prevalentes em pesquisa desenvolvida por Coutinho et al. (2006). Existem muitos resultados correspondentes a estes, mas embora a maior incidência de mastite ocorra pelas espécies coagulases negativas, são as coagulases positivas que normalmente são consideradas como as mais importantes envolvidas em todas as formas de mastite (RADOSTITS et al. 2002; SILVA et al. 2006; MORANDI et al. 2007), principalmente pelos prejuízos causados ao rebanho e também porque possuem cepas enterotoxigênicas no leite, sendo este, destinado ao consumo humano é preocupante, pois pode desencadear um quadro de gastrenterite aguda, podendo levar a óbitos, principalmente em pessoas com imunidade comprometida como idosos e neonatos (ALMEIDA, 2004).

Além disso, estes SCP apresentam maior resistência ao tratamento, podendo evoluir para uma infecção sistêmica mais grave. Os SCP podem ainda produzir leucotoxinas, capazes de destruir os monócitos e os neutrófilos polimorfonucleares, comprometendo a imunidade do animal e também secreta um exopolisacarídeo capaz de formar uma barreira que impede a ação da resposta imune e dos quimioterápicos, daí a sua maior resistência ao tratamento (CONTRERAS et al. 2007).

Os Staphylococcus freqüentemente causam mastite e são encontrados colonizando a pele da glândula mamária, tetas e lesões nessas áreas, porém, quartos mamários infectados são o principal reservatório desses microrganismos, sendo transmitido por qualquer forma de contato (PRESTES et al. 2002).

$\mathrm{Na}$ mastite infecciosa os microrganismos podem atingir a glândula mamária através de duas vias de infecção: a via descendente, através do fluxo sanguíneo e linfático e a via ascendente, a forma mais comum de penetração de microrganismos patogênicos na glândula mamária, como por exemplo, o estafilococos, o estreptococos e os coliformes (PAES, 2000).

Quanto ao processo inflamatório desencadeado na glândula mamária, as mastites são classificadas em clínica, subclínica e crônica. A Mastite clínica 
COSTA, C.R.M. et al. Mastite caprina: etiologia e epidemiologia: revisão de literatura. PUBVET, Londrina, V. 7, N. 8, Ed. 231, Art. 1530, Abril, 2013.

apresenta alterações visíveis na glândula mamária, como edema e vermelhidão e o leite fica ralo ou apresenta grumos, pus e sangue. A Mastite subclínica não apresenta alterações visíveis na glândula mamária, mas ocorrem perdas significativas na produção e qualidade do leite, que fica com menos proteína, gordura, lactose e há aumento dos teores de sódio e cloretos, que são prejudiciais, e estas são as mastites recorrentes. A mastite crônica é de cura difícil, principalmente durante a lactação, por isso, é importante o tratamento na secagem da vaca.

A mastite subclínica é a que apresenta maior importância epidemiológica, pois pode estar presente no rebanho sem que sejam percebidas alterações macroscópicas à inspeção do úbere ou de sua secreção (AZEVEDO et al. 2006; KOOP et al. 2010). Embora a mastite clínica seja responsável por perdas expressivas, uma vez que o processo inflamatório é aparente, é a mastite subclínica que assume elevada importância econômica em decorrência dos prejuízos na produção, uma vez que pode rescindir, além disso, os sintomas não são aparentes e é a mastite de maior ocorrência.

Pesquisas demonstram que a mastite do tipo subclínica, é a que mais predomina nos rebanhos de pequenos ruminantes, cuja prevalência estimada está entre 5-30\%, podendo ser ainda maior. Também representa um constante risco de infecção para todo o estoque de animais (ISLAM et al. 2011).

O animal apresenta como principais sintomas internos, anorexia, desidratação, depressão, febre e sintomas de toxemia (BURFOS, 2008). Devese ressaltar que ainda são necessários mais estudos de mastite em caprinos, uma vez que ainda são escassos (CONTRERAS et al. 2007).

Em relação ao diagnóstico da mastite, é constituído de várias etapas, para se ter um diagnóstico conclusivo. Geralmente se inicia pelo exame físico, que corresponde à inspeção e palpação do úbere, e posteriormente por exames complementares que avaliem a presença de células de defesa no leite e ainda o exame microbiológico para isolamento de agentes patogênicos; e 
COSTA, C.R.M. et al. Mastite caprina: etiologia e epidemiologia: revisão de literatura. PUBVET, Londrina, V. 7, N. 8, Ed. 231, Art. 1530, Abril, 2013.

para se avaliar a eficácia dos tratamentos, é realizado o antibiograma na seleção de drogas empregadas na terapia (ERSKINE et al. 2004).

A mastite clínica possui sintomas aparentes como região pélvica edemaciada, quente e dolorida ao toque; mudanças no tamanho e presença de tecido cicatricial podem ser detectados mais facilmente.

O leite também deve ser avaliado pela sua aparência; os primeiros jatos de leite permitem a deteç̧ão de anormalidades, como alterações na coloração (aguado), grumos, ou coágulos (TOZZETTI et al., 2008; BLAGITZ et al. 2008).

Além dos exames clínicos são essenciais os exames laboratoriais. Esses diagnósticos baseiam-se na identificação do agente etiológico (MOTA, 2008).

Vários testes podem ser utilizados para determinar a mastite, principalmente a forma sub-clínica; a contagem indireta de células somáticas (CCS) no leite, através da utilização do California Mastitis Test (CMT), ou através da contagem direta de células somáticas utilizando equipamentos eletrônicos ( MOTA, 2008).

Através da CCS é possível identificar diferenças entre caprino e ovinos e que podem interferir no diagnóstico preciso da mastite. Em caprinos geralmente o CCS é alto, às vezes, mesmo em cabras não infectadas, isso ocorre em decorrência do processo apócrino de eliminação glandular dos caprinos além de outros fatores que não estão intimamente relacionados a processos infecciosos e sim fisiológicos (PAAPE et al. 2001; AYDIN et al. 2009). De acordo com Peixoto et al. (2010) em virtude destas diferenças a utilização do CMT para o diagnóstico da mastite sub-clínica em cabras e ovelhas deverá sempre ser associado à técnica da lactocultura, para maior confiabilidade dos resultados.

No Teste Califórnia mastite, o leite de cada quarto é misturado com uma solução de detergente. O leite de quartos infectados forma um gel; a consistência do gel é avaliada visualmente (PAAPE et al. 2001; SILVA et al. 2001). Essa reação é relacionada ao número de células somáticas no leite, e uma reação positiva indica mastite. 
COSTA, C.R.M. et al. Mastite caprina: etiologia e epidemiologia: revisão de literatura. PUBVET, Londrina, V. 7, N. 8, Ed. 231, Art. 1530, Abril, 2013.

Com relação ao isolamento bacteriano é um método importante de diagnóstico, mas sua confiabilidade está na forma como é desenvolvido o procedimento desde a coleta (SILVA et al. 2004).O leite deve ser coletado antes da ordenha, após lavagem e cuidadosa anti-sepsia dos tetos com álcool a $70 \%$, sendo que os três primeiros jatos devem ser desprezados. Os frascos onde o leite é coletado devem ser estéreis, e o transporte até o local do processamento deve ser cuidadoso. Após crescimento pode-se fazer identificação das bactérias por suas características morfológicas, bioquímicas e tintoriais.

Também se costuma fazer antibiograma pelo método de difusão em disco, em sub-cultivo utilizando ágar Müller Hinton para analisar a sensibilidade dos microrganismos isolados a vários tipos de antibióticos. Este teste de sensibilidade é muito importante, principalmente diante da presença de S. Aureus, pois de acordo com Brito et al. (2001); Medeiros et al. (2009) vários estudos com este tipo de bactéria demonstraram resistência destes microrganismos a vários tipos de antibióticos.

Após um diagnóstico microbiológico conclusivo a mastite pode ser curada por tratamento com antibióticos. Em estudo realizado por Coutinho et al. (2006) a associação neomicina+bacitracina+tetraciclina e a ciprofloxacina foram os antibióticos mais eficazes para o tratamento da mastite causada por Staphylococcus. A associação de antibióticos é comum no tratamento da mastite, visando potencializar a ação dos mesmos, diminuir efeitos indesejáveis e aumentar o espectro de ação sobre os microrganismos. Neste mesmo estudo foi identificado maior resistência dos microrganismos aos antibióticos penicilina, ampicilina e neomicina.

Adicionalmente estão disponíveis produtos comerciais elaborados especificamente para o uso na terapia de pequenos ruminantes, restando, na prática, a alternativa de uso de antimastíticos idealizados para espécie bovina (COUTINHO et al. 2006).

A via de administração intramamária é o método de escolha mais comum para o tratamento de mastite clínica ou sub-clínica, permitindo aplicações de 
COSTA, C.R.M. et al. Mastite caprina: etiologia e epidemiologia: revisão de literatura. PUBVET, Londrina, V. 7, N. 8, Ed. 231, Art. 1530, Abril, 2013.

pequenas quantidades de agentes antimicrobianos diretamente no local da infecção (MASSEI et al. 2008).

O antibiótico usado para tratar mastite é uma preocupação importante para a indústria e para a saúde pública, porque eles podem trazer mudanças na composição do leite (redução em cálcio, fósforo, proteína e gordura, e aumento em sódio e cloro) reduzindo, portanto, a sua qualidade (ISLAM et al. 2011). Além disso, A presença de resíduo de antibiótico no leite interfere com o processo de manufaturação de muitos produtos lácteos (queijo e outros produtos fermentáveis). Os sabores indesejáveis reduzem o valor dos produtos lácteos e a presença de antibióticos mesmo sendo de níveis baixos pode causar problemas de saúde nos consumidores (TOZZETTI et al. 2008).

Por isso, o mais importante é prevenir da mastite, o ideal é adotar programas voltados para o controle desta doença em rebanhos caprinos objetivando diminuir a sua prevalência a níveis pelo menos aceitáveis, uma vez que sua erradicação completa não é possível.

São importantes para isso adoção de medidas higiênicas indicadas durante a ordenha para reduzir os índices de infecção da glândula mamária.

Um programa de controle de mastite deverá visar: reduzir as infecções pré-existentes; vacas com mais de três casos clínicos por lactação, que não respondem ao tratamento de "vaca seca", deverão ser descartadas; diagnóstico e tratamento precoce dos casos clínicos; tratamento de mastite sub-clínica na interrupção da lactação; manejo e higiene de ordenha corretos; desinfecção pós-ordenha adequada; manutenção adequada do equipamento de ordenha; monitoramento dos casos de mastite clinica e o nível de mastite subclinica periodicamente (MASSEI et al. 2008; TOZZETTI et al. 2008).

\section{CONCLUSÕES}

Estudos de revisão como este fornecem dados importantes sobre a etiologia, epidemiologia, diagnóstico, tratamento e controle dos microrganismos que desencadeiam a mastite. 
COSTA, C.R.M. et al. Mastite caprina: etiologia e epidemiologia: revisão de literatura. PUBVET, Londrina, V. 7, N. 8, Ed. 231, Art. 1530, Abril, 2013.

É importante desenvolver programas de controle e tratamento desta afecção em cabras, para melhorar a qualidade e a quantidade de leite, além de diminuir custos na produção. Do ponto de vista sanitário do leite maior segurança no consumo.

A mastite é um grande problema para os produtores de leite, havendo necessidade de adoção de práticas higiênicas em ordenha e manejo. Por isso os artigos revisados apontam sempre pela necessidade de intensificação de medidas de profilaxia e controle para microrganismos.

\section{REFERÊNCIAS}

ALMEIDA, L.A.B. 2004. Avaliação do tratamento alopático e homeopático de mastite bovina em animais inoculados com Staphylococcus aureus. Dissertação de mestrado, Faculdade de Medicina Veterinária e Zootecnia, São Paulo. 104p.

ANDERSON, D.E. et al. Enfermidades da glândula mamária, p.379-399. In: Pugh D.G. (Eds), Clínica de Ovinos e Caprinos. Roca, São Paulo. 2004.

ARAÚJO, D.K.G. \& GHELLER, V.A. 2005. Aspectos morfológicos, celulares e moleculares da imunidade da glândula mamária de búfalas (Bubalus bubalis): revisão de literatura. Revista Brasileira de Reprodução Animal. 29(2): 77-83.

AULRICH, K. \& BARTH, K. 2008. Intramammary infections caused by coagulase-negative staphylococci and the effect on somatic cell counts in dairy goats. Agriculture and Forestry Research. 59(58): 59-64.

AZEVEDO, E.O. et al. 2006. Contagious agalactia by Mycoplasma agalactiae in small ruminants in Brazil: First report. Braz. J. Microbiol. 37(1): 576-581.

AYDIN, I. et al. 2009. Identification and antimicrobial susceptibility of subclinical mastitis Pathogens Isolated from Hair Goats Milk. Journal of Animal and Veterinary Advances, 8(6): 1086-1090.

BERGONIER, D. \& BERTHELOT, X. 2003. New advances in epizootiology and control of ewe mastitis. Livestock Prod. Sci., 79(1): 1-16.

BLAGITZ, M.G. et al. 2008. Perfil celular e microbiológico do leite de ovelhas Santa Inês no período lactante e pós-desmame. Pesq. Vet. Bras. 28(9): 417-422.

BRITO, M.A.V.P. et al. 2001. Concentração mínima inibitória de dez antimicrobianos para amostras de Staphylococcus aureus isoladas de infecção intramamária bovina. Arq. Bras. Med. Vet. Zootec. 53(5): 531-537.

BURFOS, F.R.N.F. et al. 2008. Mastectomias parciais em cabras com mastite gangrenosa unilateral, diagnosticadas na clínica de grandes animais da Universidade Federal Rural de Pernambuco (UFRPE). Ciênc. vet. tróp. 11(1): 30-35. 
CONTRERAS, A. et al. 2007. Mastitis in small ruminants. Small Ruminant Research. 68(1): 145-153.

CORDEIRO, P.R.C. 2006. Mercado do leite de cabra e de seus derivados. Revista do Conselho Federal de Medicina Veterinária. 12(39): 32-43.

COUTINHO, D.A. et al. 2006. Etiologia e sensibilidade antimicrobiana in vitro de bactérias isoladas de ovelhas da raça Santa Inês com mastite subclínica. Rev. Bras. Saúde Prod. 7(2): 139-151.

ERSKINE, R.J. et al. 2004. Bovine mastitis pathogens and trends in resistance to antibacterial drugs. National Mastitis Council. 1(1): 400-414.

FRANDSON, R.D. et al. 2005. Anatomia e fisiologia das glândulas mamárias. p.399-410. In: FRANDSON, R. D.; WILKE, W. L.; FAILS, A. D. (7a ed.) Anatomia e fisiologia dos animais de fazenda. Guanabara Koogan, Rio de Janeiro.

FREITAS M.F.L. et al. 2005. Perfil de sensibilidade antimicrobiana in vitro de Staphylococcus coagulase positivos isolados de leite de vacas com mastite no agreste do estado de Pernambuco. Arqs. Inst. Biológico. 72(2): 171-177.

GOMES, V. et al. 2004. Influência do estágio de lactação na composição do leite de cabras (Capra hircus). Brazilian Journal of Veterinary Research and Animal Science, 41(5): 339-342.

HURLEY, W.L. \& MORIN, D.E. Capturado em 10 de agosto de 2011. Factors affecting susceptibility to mastitis. Lactation biology. On line. Disponível na internet http://www.classes.aces.uiuc.edu/AnSci30 8/.

ISLAM, M.R. et al. 2012. Identification and Antibiotic Sensitivity of the Causative Organisms of Sub-clinical Mastitis in Sheep and Goats. Pakistan Veterinary Journal. 32(2): 179-182.

KOOP, G. et al. 2010. The effect of subclinical mastitis on milk yield in dairy goats. J. Dairy Sci. 93(12): 5809-5817.

LANGONI, $\mathrm{H}$. et al. 2006. Mastite caprina: seus agentes e sensibilidade frente a antimicrobianos. Rev. Bras. Ciênc. Vet. 13(1): 51-54.

MASSEI et al. 2008. Mastite - diagnóstico, tratamento e prevenção: revisão de literatura, Revista Científica Eletrônica de Medicina Veterinária. 6(10): 1-6.

MEDEIROS, E.S. et al. 2009. Perfil de sensibilidade microbiana in vitro de linhagens de Staphylococcus spp. isoladas de vacas com mastite subclínica. Pesq. Vet. Bras. 29(7): 569574.

MORANDI, S. et al. 2007. Detection of classical enterotoxins and identification of enterotoxin genes in Staphylococcus aureus from milk and dairy products. Veterinar y Microbiology, 124(12): $66-72$.

MORONI, P. et al. 2005. Characterization of Staphylococcus aureus isolated from chronically infected dairy goats. J. Dairy Sci. 88(10): 3500-3509.

MOTA, R.A. 2008. Aspectos epidemiológicos, diagnóstico e controle das mastites em caprinos e ovinos. Tecnol. Ciênc. Agropec. 2(3): 57-61. 
PAAPE M.J. et al. 2001. Milk somatic cells and lactation in small ruminants. J. Dairy Sci. 84(1) : E237-E244.

PAES, P.R.O. et al. 2000. Efeitos da administração de vitamina E na infecção mamária e na contagem de células somáticas de cabras primíparas desafiadas experimentalmente com Staphylococcus aureus. Arq. Bras. Med. Vet. Zootec. 55(1): 15-20.

PEIXOTO, R.M. et al. 2010. Etiologia e perfil de sensibilidade antimicrobiana dos isolados bacterianos da mastite em pequenos ruminantes e concordância de técnicas empregadas no diagnóstico. Pesq. Vet. Bras. 30(9): 735-740.

PRESTES, D.S. et al. 2002. Susceptibilidade à mastite: fatores que a influenciam: uma revisão. Revta FZVA. 9(1): 118-132.

RADOSTITS, O.M.; et al. 2002. Mastite. p.541-629. In: RADOSTITS, O. M. Clínica veterinária: um tratado de doenças dos bovinos, ovinos, suínos, caprinos e eqüinos. 9ed. Guanabara Koogan, Rio de Janeiro.

SHEARER, J.K. Teat lesions can lead to milking problems, mastitis. Capturado em 10 de agosto de 2011. On line. Disponível na internet http://www.nmconline.org/archives.htm.

SILVA, E.R. et al. 2006. Coagulase gene polymorphism of Staphylococcus aureus isolated from goat mastitis in Braz ilian Dairy Herds. Letters in Applied Microbiology. 42(1): 30-34.

SILVA, E.R. et al. 2001. Associação entre o California Mastitis Test e a Contagem de Células Somáticas na avaliação da saúde da glândula mamária caprina. Braz. J. vet. Res. anim. Sci. 38(1): 46-48.

SILVA, E.R. et al. 2004. Identification and in vitro antimicrobial susceptibility of Staphylococcus species isolated from goat mastitis in the Northeast of Brazil. Small Rumin. Res. 55(1-3): 4549.

TOZZETTI, D.S et al. 2008. Prevenção, controle e tratamento das mastites bovinas - revisão de literatura. Revista Científica Eletrônica de Medicina Veterinária. 6(10): 1-7. 